\title{
OS PROFESSORES DOS ANOS INICIAIS E O ENSINO CIÊNCIAS POR INVESTIGAÇÃO: CONCEPÇÕES, POSSIBILIDADES E DESAFIOS INICIAIS
}

\author{
Ronaldo Santos Santana, Fernanda Franzolin \\ Universidade Federal do ABC \\ Santo André, São Paulo \\ E-mail: prof.ronaldosantana@gmail.com, Fernanda.franzolin@ufabc.edu.br
}

\section{Rodolfo Pereira Correia Marinho}

Somos Educação

São Paulo, São Paulo

E-mail: rodolfomarinho@somoseducacao.com.br

Resumo: O presente artigo tem como objetivo investigar as concepções, possibilidades e desafios encontrados por professores dos Anos Iniciais do Ensino Fundamental ao desenvolverem atividades investigativas. Tais professores participaram de um processo formativo desenvolvido na Universidade Federal do ABC. Para atingir o objetivo, foi utilizada a transcrição de episódios videogravados do curso de formação, entrevistas e formulários respondidos pelos cursistas. Esses materiais são registros de avaliação do citado curso, utilizados com a devida autorização. Como referencial para o processamento e análise dos dados, foram utilizadas as contribuições para análise de dados qualitativos e foi realizada também uma análise de conteúdo do material transcrito. Foram evidenciados desafios na implementação $d$ atividades investigativas, dentre eles estão em destaque a escassez de materiais disponíveis aos professores para implementarem este tipo de proposta, um repertório escasso de ideia dos professores, a ausência de espaço apropriado em algumas escolas e a necessidade de auxílio de outras pessoas. Os professores evidenciaram alguns desafios enfrentados, como, por exemplo, aproveitar o "erro" em atividades investigativas e problemas com a inserção das mesmas na rotina escolar. Foram encontradas também diversas potencialidades, como a possibilidade de atrelar o ensino de Ciências ao ensino de outras disciplinas por meio das atividades investigativas, possibilitar atuação mais autônoma do aluno no processo de aprendizagem e proporcionar autonomia discente para a criação de novas investigações e a metodologia. Tais elementos evidenciados devem ser estudados por mais pesquisadores em diferentes contextos para que se possa ter cada vez mais clareza deste fenômeno. Se realizadas, essas pesquisas contribuiriam com o trabalho de professores que decidam implementar atividades investigativas e de formadores que ministram cursos de formação continuada. Além disso, fundamentariam também a literatura da área e os documentos oficiais que regem a educação.

Palavras-chave: ensino de ciências por investigação, anos iniciais, ensino fundamental.

\section{ELEMENTARY SCHOOL TEACHERS AND THE INQUIRY-BASED LEARNING IN SCIENCES: INITIAL CONCEPTIONS, OPPORTUNITIES AND CHALLENGES}

Abstract: This currently article aims to investigate the concepts, possibilities and challenges faced by teachers of the Elementary Schools to develop inquiry-based activities. These teachers 
participated of a training process developed at the Universidade Federal do ABC. To reach the goal, the training course used the videotaped transcription, recorded during the training time, interviews and forms answered by the course participants. These materials are evaluation records of the course, used with under complete permission. As a reference for processing and data analysis, the contributions to qualitative data and a transcribed material content analysis was used. About the inquiry-based activities implementation, challenges were encountered, among which are highlighted the scarcity of available material for teachers to implement such a proposal, a meager repertoire of view of teachers, lack of appropriate space in some schools and the need for aid others. Teachers showed some challenges, for example, take advantage of the "error" in inquirybased activities and problems with the inclusion of the same in the school routine. Several possibilities were found, such as the ability to harness science teaching to teaching other subjects through the inquiry-based activities, enabling an autonomous role to the student in the learning process and provide student autonomy to create new investigations and methodology. All these highlighted elements should be studied by other researchers in different contexts so that we can have more clarity of this phenomenon. If carried out, such research would contribute to the work of teachers who decide to implement inquiry-based activities and trainers who teach continuing education courses activities. They will also support the literature of the area improving the official documents which rules education.

Keywords: inquiry based teaching, first years, elementary school.

Recebido em 25/04/2016. Publicado em 31/12/2016. 


\section{INTRODUÇÃO}

Pesquisas em âmbito nacional e internacional evidenciam desafios da atividade docente em diferentes aspectos. Gouw, Franzolin e Fejes (2013) e Colombo Junior et al. (2013) afirmam que a formação inicial dos professores dos Anos Iniciais pode ser um desafio no que se refere ao ensino de Ciências, pois os cursos de Pedagogia podem não apresentar uma base considerável para as práticas do ensino de Ciências e, raramente, tópicos relacionados ao ensino de ciências são abordados em cursos de formação continuada. Godoy, Segrra e Mauro (2014) afirmam que, mesmo tendo acontecido consideráveis mudanças nos documentos oficiais que regem a educação a nível nacional, ainda há desigualdade entre os resultados das pesquisas, os documentos curriculares e o que de fato acontece na sala de aula.

Por isso, Godoy, Segrra e Mauro (2014) reforçam a importância de se produzir ações para a formação docente que possam trazer contribuições para o ensino e diminuir os desafios que os professores enfrentam nos Anos Iniciais de escolarização. As autoras recomendam o ensino de Ciências por investigação como uma alternativa didática que pode ser significativa para a promoção de um ensino de Ciências com qualidade. Na prática, o ensino por investigação é implementado por meio das atividades investigativas (Als).

$\mathrm{Na}$ literatura, é possível encontrar pesquisas que utilizam as Als com diferentes abordagens, todavia, alguns autores (CARVALHO, 2013; ZOMPERO; LABURÚ, 2010; ZANON; FREITAS, 2007, entre outros) apontam algumas características que são comuns a tais atividades. Segundo os pesquisadores, geralmente as atividades investigativas iniciam com a proposição de um problema ou uma pergunta de investigação que é proposta pelo professor ou pelos próprios alunos. A questão da proposição de uma pergunta de investigação é essencial em tais atividades e é recomendável que o problema seja contextualizado. Após essa etapa, os alunos se envolvem e formulam hipóteses para solucionar essa situação conflitante e, neste momento, os professores podem conhecer as concepções prévias dos alunos.

Além disso, os discentes podem manusear dados por meio de atividades experimentais práticas ou pesquisas bibliográficas, buscando encontrar informações que os ajudem a resolver o problema proposto. Com a reunião e análise dos dados, os alunos podem chegar a conclusões ou considerações finais que serão divulgadas e discutidas em grupos. Após a resolução do problema, 
uma atividade de sistematização do conhecimento construído pelos alunos se faz necessária, assim, o problema inicial é retomado e discutido em grupo, havendo comparações entre as hipóteses que eles tinham formulado inicialmente e o conhecimento adquirido ao final.

Oliveira (2013) afirma que à medida que os alunos vão entrando em contato com atividades investigativas, por meio de aulas práticas ou não, e possam realizar discussões e registros escritos ao decorrer das sequências de ensino, mais próximos da investigação científica e da alfabetização científica esses estudantes estarão. Segundo Krasilchik e Marandino (2007), alunos cientificamente alfabetizados são capazes não só de entender a linguagem da Ciência, mas de assimilar conceitos, utilizando-os no momento e em contextos oportunos. Além disso, segundo Carvalho (2013), as sequências de ensino investigativo, quando de acordo com os referenciais teóricos, podem levar os alunos ao processo de alfabetização científica. No entanto, as autoras ressaltam que os alunos não se comportarão como cientistas em um laboratório, uma vez que eles ainda não têm fundamentação teórica, idade e nem conhecimento conceitual para isso.

Minstrell e van Zee (2000) argumentam que os alunos necessitam aprender a ver o mundo de forma questionadora e crítica e que, para isso, o professor deve promover situações em sala de aula que possibilitem a investigação. Segundo Capecchi (2013), para despertar a natureza investigativa nos alunos é necessário criar condições para que as situações do cotidiano sejam vistas com um olhar problematizador e crítico. Para que os alunos entrem em contato com os conteúdos que são abordados em sala de aula e percebam que há possibilidade de investigação dentro do espaço escolar e que os conhecimentos apresentados não são verdades absolutas ou "conteúdos acabados".

Apesar das atividades investigativas não garantirem sempre o conflito cognitivo e a mudança conceitual, ou seja, a substituição das concepções iniciais dos alunos pelas concepções dos cientistas (MORTIMER, 2000), há autores que defendem que as Als quando utilizadas podem contribuir positivamente na construção de conceitos. Sobre esta possibilidade, Carvalho (1997) afirma que, durante uma sequência investigativa, discussões podem ser realizadas permitindo o aluno passar da "ação manipulativa para a ação intelectual", onde o aluno toma consciência do que fez e como fez, passando a argumentar e, possivelmente, justificar os resultados obtidos. Neste momento, o aluno pode construir conhecimentos e refletir sobre aquilo que foi realizado 
durante a sequência investigativa. Lamonato e Passos (2012) também consideram que as Als possibilitam ao aluno aprimorar aqueles conceitos que ele já traz para a sala de aula, além de construir e reconstruir novos conceitos, conforme seja necessário.

Além do aprendizado conceitual, as Als também podem propiciar a aprendizagem de procedimentos (BORGES, 2002; ZÔMPERO; LABURÚ, 2011; COLOMBO JUNIOR et al., 2013, entre outros), possibilitando o desenvolvimento intelectual do aluno. Elas possuem um grande potencial argumentativo e podem aguçar a curiosidade das crianças, fazendo-as procurar explicações, conquistar novas descobertas e fazer relações entre o cotidiano e o conhecimento científico (COLOMBO JUNIOR et al., 2013). De acordo com Bybee (2000), o ensino de Ciências com uma abordagem investigativa pode propiciar também condições para o aluno entender a natureza da Ciência e como o conhecimento científico é construído.

Resultados obtidos por meio das pesquisas de Carvalho (1997), Colombo Junior et al. (2012), Gouw, Franzolin e Fejes (2013), Lamonato e Passos (2012) e Zanon e Freitas (2007) demonstraram que há possibilidades de se trabalhar as Als nos Anos Iniciais, desde que se adeque a estrutura da sequência didática à faixa etária dos alunos. A participação do aluno em tais atividades dependerá do nível e dos conhecimentos que ele possuir. Em atividades investigativas com estudantes dos Anos Iniciais, o nível dos problemas propostos e a autonomia podem ser diferentes de uma Al com foco para os anos finais do Ensino Fundamental e Ensino Médio (GOUW; FRANZOLIN; FEJES, 2013).

De acordo com Carvalho (1997), nas atividades investigativas os alunos se envolvem e um clima de investigação em sala de aula é criado, pois há um problema a ser resolvido e também há a possibilidade de manipular materiais, criar hipóteses, testá-las, trabalho coletivo e discussões entre colegas e o professor. Segundo Lamonato e Passos (2012), as Als possibilitam ao professor o conhecimento sobre o que os alunos sabem, conhecimento a respeito do conteúdo e conhecimento sobre a capacidade investigativa que eles possuem.

São diversas as possibilidades evidenciadas pelas pesquisas e muito se tem pesquisado, no Brasil e no exterior, sobre o ensino de Ciências por investigação e as atividades investigativas (CARVALHO ET AL., 2013; GOUW; FRANZOLIN; FEJES, 2013; COLOMBO JUNIOR et al., 2012; WHEELER, 2000; BYBEE, 2000; MINSTRELL; VAN ZEE, 2000; GIL-PERÉZ, 1993, entre outros). Segundo Van Zee et al. 
(2005) os professores se conscientizarão dos resultados e possibilidades das atividades investigativas somente se forem motivados a fazê-las.

Não podemos deixar de ressaltar, também, que são dadas recomendações nos documentos oficiais nacionais e internacionais para a utilização de atividades investigativas nos Anos Iniciais (GOUW; FRANZOLIN; FEJES, 2013). De acordo com Colombo Junior et al. (2012) e Zômpero e Laburú (2011), no Brasil, o ensino de Ciências com a utilização das Als é pouco presente nos Anos Iniciais e poderia ser mais enfatizado nos documentos oficiais de ensino. No contexto brasileiro, as atividades investigativas e o ensino de Ciências, na maioria das vezes e por diversos fatores, podem ser deixados em segundo plano, priorizando-se o ensino de Português e Matemática.

A literatura tem apontado alguns desafios na implementação de atividades investigativas nos Anos Iniciais. Para Colombo Junior et al. (2013), Gouw, Franzolin e Fejes (2013) e Welch et al. (1981), a formação inicial dos professores pode ser um desafio no que tange ao ensino de Ciências, já que os cursos de Pedagogia podem não apresentar uma base considerável para as práticas do ensino de Ciências. Raramente os tópicos relacionados a essa disciplina são abordados em cursos de formação continuada e os professores podem se sentir desconfortáveis ao trabalhar com as atividades investigativas. Segundo Van Zee et al. (2005) os professores do Ensino Fundamental podem ter uma visão negativa em relação à Ciência, principalmente quando relacionados com os fenômenos da física, por exemplo. No entanto, em sua pesquisa, os autores demonstram algumas possibilidades para se alterar essa concepção negativa.

Os autores supracitados argumentam que, depois da experiência dos professores em um processo formativo, foi possível perceber que eles têm muito conhecimento sobre o "mundo da física". E como tais conhecimentos partem do seu cotidiano, eles podem realizar atividades investigativas relacionadas às Ciências de maneira produtiva, desde que sejam encorajados a isso. Outra dificuldade identificada nas pesquisas é estruturar as Als para que elas possam ir ao encontro das ideias de autores que pesquisam sobre modelos de aprendizagem participativa (GOUW; FRANZOLIN; FEJES, 2013).

Zanon e Freitas (2007) argumentam que muitas vezes as práticas pedagógicas adotadas pelos professores envolvem métodos engessados que não estimulam a investigação e a proposição de questionamentos e observações. Esse fato pode resultar em dificuldades no momento em que 
esse professor optar por aplicar uma atividade investigativa. Colombo Junior et al. (2013) afirmam que os desafios na implementação das Als, muitas vezes, são impostos não só pela complexidade dos conceitos das Ciências (principalmente referente à Física), mas também por insegurança dos docentes frente a possíveis mudanças em suas práticas pedagógicas. Os autores afirmam também que o sistema de ensino pode agir de modo a dificultar ou impedir a inovação dentro da sala de aula, tornando o professor impossibilitado para o advento de novos métodos para ensinar.

Pesquisadores identificaram que também é um desafio fomentar o interesse nos alunos pelas atividades investigativas de forma que as iniciativas venham deles próprios (GOUW; FRANZOLIN; FEJES, 2013). Outra questão dificultante é que as escolas podem até mesmo dispor de equipamentos e recursos para a realização de atividades investigativas, no entanto, pela falta de atividades já preparadas, falta de tempo do professor para planejar a realização dessas atividades e a falta de recurso para a reposição dos materiais, muitas vezes as Als são deixadas de lado (BORGES, 2002).

Apesar de haver diversos pesquisadores que estudam diferentes aspectos relacionados às Als, são importantes as pesquisas que se debruçam especificamente nas possibilidades e desafios de sua implementação. Tais pesquisas promovem as potencialidades do ensino por investigação, fundamentam outras pesquisas e promovem reflexão sobre os desafios para se traçar possíveis soluções. O fenômeno de implementação das atividades investigativas na sala de aula é complexo e, apesar de haver algumas pesquisas que trazem dados iniciais sobre o tema, este trabalho pretende enriquecer o quadro investigativo. Acreditamos que tal contribuição é importante, já que compreender as dificuldades e as possibilidades na implementação das atividades investigativas colabora com pesquisadores da área e embasa a prática pedagógica de professores.

Sendo assim, o objetivo da presente pesquisa é investigar as concepções e práticas iniciais de professores dos Anos Iniciais que participaram de um processo formativo sobre atividades investigativas, evidenciando as possibilidades e dificuldades enfrentadas na implementação de atividades investigativas à sua prática. Espera-se que, ao se unir os dados evidenciados nesta pesquisa com outros estudos já iniciados, seja possível alcançar maior clareza acerca deste fenômeno para que tanto professores quanto pesquisadores reflitam e discutam sobre todos os 
aspectos relacionados ao ensino por investigação, tais como os desafios e possibilidades enfrentadas.

\section{PERCURSO METODOLÓGICO}

Apesar de essa pesquisa possuir alguns dados quantitativos, trata-se, em sua maior parte, de uma pesquisa qualitativa. De acordo com as considerações de Ludke e André (1986), é comum nesse tipo de pesquisa ter-se o ambiente natural como fonte de dados e o pesquisador como instrumento principal. No que diz respeito aos dados, eles são predominantemente descritivos, há uma preocupação maior com o processo em relação ao produto. A atenção do pesquisador se volta ao "significado" que as pessoas dão às coisas e, no momento de análise dos dados, o processo tende a ser indutivo. A maior preocupação era entender o fenômeno em contextos específicos e em sua complexidade, assim, tais recursos foram utilizados para entender o processo e não apenas o produto.

Como fonte dos dados foram utilizados os registros de avaliação de um curso de extensão, sendo eles um questionário de concepções prévias (anexo I) preenchido pelos cursistas e as transcrições das videogravações de um curso de formação continuada. O curso era intitulado: Oficina Pedagógica - ensinando Ciências com atividades investigativas. Foi um curso de extensão universitária ministrado pela docente coordenadora do GPEnCiBio (Grupo de Pesquisa em Ensino de Ciências e Biologia - UFABC), financiado pela Pró-reitora de Extensão desta mesma instituição de Ensino Superior. No curso, 37 interessados se inscreveram e destes 20 puderam ser selecionados para participar do curso. Os cursistas eram professores dos Anos Iniciais do Ensino Fundamental ou profissionais que trabalhavam com tal nível de ensino em um município da região metropolitana de São Paulo. Tais encontros formativos tinham o objetivo de oferecer aos cursistas atuantes nos Anos Iniciais os subsídios teóricos e metodológicos para compreender o que são as atividades investigativas, sua importância para o ensino de Ciências e quais as possibilidades de desenvolver um trabalho com a metodologia apresentada. As oficinas aconteceram em cinco encontros quinzenais entre abril e julho de 2015.

Durante o curso, foram realizadas discussões sobre o conceito, metodologia e importância das atividades investigativas no ensino de Ciências. Os cursistas interagiam com tais atividades, implementavam em suas classes e posteriormente discutiam a experiência com os demais colegas 
nos encontros. Para atingir o objetivo desta pesquisa, foram utilizados os dados coletados no primeiro e no segundo encontro.

No primeiro dia de curso, a formadora e os professores tiveram uma discussão teórica sobre o conceito de atividades investigativas, sua importância, as diferenças entre um experimento investigativo e um demonstrativo e visualizaram exemplos práticos de atividades investigativas e demonstrativas. Os cursistas participaram de algumas atividades experimentais, analisaram as diferenças entre elas e identificaram os aspectos que as caracterizam ou não como investigativas. Além de observarem os níveis diferenciados de participação dos alunos dentro de cada proposta, os participantes foram convidados a realizar, fora do horário do curso, uma investigação sobre o desenvolvimento da Drosophila melanogaster, conhecida como mosca-das-frutas. Esta ação poderia ser realizada pelo cursista ou levada às suas respectivas salas de aula para aplicação com os alunos.

Portanto, inicialmente os professores conheceram aspectos das atividades investigativas para posteriormente as implementarem em suas aulas, trazendo, no segundo encontro, contribuições após uma experiência prática da implementação de Als. No segundo encontro, os cursistas socializaram o experimento realizado nos dias anteriores e realizaram uma discussão sobre o papel das Als e seu caráter investigativo, os tipos de perguntas investigativas e como são analisados os experimentos "errados".

Conforme mencionado anteriormente, foram analisadas as respostas dos professores ao questionário de concepções prévias preenchido pelos cursistas no ato de inscrição. $E$, neste, esperava-se obter dados dos professores cursistas sobre a frequência de aplicação de atividades investigativas com suas respectivas turmas no ano anterior e quais as dificuldades e possibilidades que eles enfrentaram. Tais dados seriam relacionados com os recolhidos no primeiro e no segundo encontro, depois que os professores discutissem aspectos teóricos e metodológicos das Als e os realizassem com seus alunos.

Para a análise dos dados qualitativos, foram utilizadas as contribuições referentes à Análise de Conteúdo (BARDIN, 2011; OLIVEIRA et al., 2003) e elementos da análise qualitativa de dados apresentados por Marshall e Rossman (2002), por ser um método de análise que permite ao pesquisador reconhecer os significados ou o conteúdo expresso por meio da fala dos sujeitos e/ou 
objetos de estudo. Segundo as autoras, a análise de dados qualitativos pode passar por sete procedimentos, sendo eles: a organização dos dados, uma imersão nos dados, a elaboração de categorias e temas, a codificação dos dados, a interpretação por meio dos memorandos, a procura por entendimentos ou interpretações alternativas e, por último, a redação de um texto que relata a pesquisa realizada.

Foi mencionado anteriormente que os dados utilizados nesta pesquisa são oriundos dos registros de avaliação de um curso de formação continuada. Após a devida autorização para a utilização de tais registros, foi realizada a transcrição dos registros em áudio e vídeo, seguida de uma organização dos mesmos para a triangulação posterior. Com todo o material devidamente organizado e formatado, foi realizada a imersão em tais registros, a fim de explorar o conteúdo, significado e conceitos que aqueles sujeitos expressam em suas falas e encontrar categorias de possibilidades e desafios. Com essa análise foi possivel evidenciar diversas categorias prévias. Após a categorização prévia, os dados, até então brutos, foram agrupados para ter-se uma compreensão mais ampla de tais categorias e relacioná-las para que pudessem ser realizadas as interpretações de tais categorias, o que resultaria na redação dos resultados da presente pesquisa. A fim de manter-se o sigilo dos sujeitos envolvidos nesta pesquisa, os professores foram identificados e mencionados como professor 1 (P1), professor 2 (P2) e assim sucessivamente.

\section{RESULTADOS E DISCUSSÃO}

A fim de organizar a redação dos resultados e discussão, permitindo uma sequência lógica, o texto será seccionado em duas seções. Na parte de concepções antes da intervenção pedagógica, serão apresentados e discutidos os dados que foram recolhidos antes do processo de formação por meio do questionário de concepções prévias que os professores responderam (anexo I). Na parte de concepções iniciais após a intervenção pedagógica, serão analisados e discutidos os dados coletados durante o primeiro e o segundo dia de formação no curso. Posteriormente, serão apresentados resultados sobre uma possível mudança conceitual na concepção dos cursistas e apresentados desafios e possibilidades que os mesmos encontraram na prática, após realizarem atividades investigativas com seus alunos. 


\subsection{Concepções antes da intervenção pedagógica}

A partir da análise dos questionários de concepções prévias das professoras cursistas, foi construído um gráfico (Figura 1) que evidencia dados sobre a frequência de desenvolvimento e aplicação das atividades investigativas implementadas pelos professores no ano anterior ao curso de formação continuada. Dos 20 professores, sujeitos da presente pesquisa, destaca-se o grupo que não realizou nenhuma atividade investigativa ( 7 de $n=20)$, estando os demais em equilíbrio. Será realizada, posteriormente, uma análise mais profunda nos dados de tais professores, a fim de se encontrar possíveis fatores que impediram a implementação das atividades investigativas no ano anterior a essa pesquisa.

Figura 1. Frequência de desenvolvimento e aplicação de Als no ano anterior ao curso de formação. Considerar $n=20$ professores.

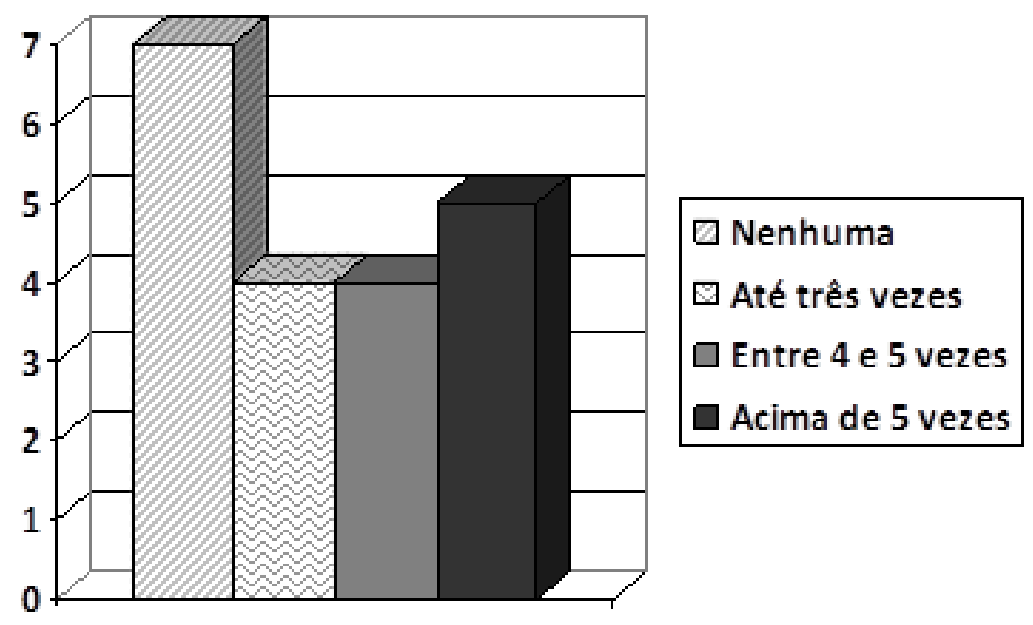

Fonte: dados da pesquisa.

Mesmo estando em destaque o número de professores que não aplicaram nenhuma atividade investigativa, a soma dos professores que declararam procurar implementá-las ultrapassa a faixa dos $50 \%$. No entanto, quando procuramos subsídios na literatura, não são encontrados tantos professores implementando Als (COLOMBO JUNIOR et al., 2012; MATOS; VALADARES, 2001; ZOMPERO; LABURÚ, 2011). Contudo, não são apenas os professores dos Anos Iniciais do Brasil que utilizam pouco as atividades investigativas ou experimentais. Em Portugal, segundo Matos e Valadares (2001) encontra-se uma realidade similar. 
De acordo com Colombo Junior et al. (2012) e Zompero e Laburú (2011), no Brasil, o ensino de Ciências com a utilização de Als está pouco presente nos Anos Iniciais e poderia ser mais enfatizado nos documentos oficiais de ensino. Segundo os autores anteriormente citados, no contexto brasileiro as atividades investigativas, na maioria das vezes e por diversos fatores, são deixadas em segundo plano, priorizando outras modalidades didáticas e disciplinas, este assunto será melhor discutido posteriormente. A terceira questão do formulário de concepções prévias, a saber, "existe algum fator que impediu você de realizar mais atividades investigativas?" (anexo I), permite coletar dados referentes aos desafios na implementação. Ao analisar os dados referentes aos desafios relatados por todos os docentes, obteve-se o seguinte gráfico (figura 2):

Figura 2. Quantidade de professores que citaram as dificuldades/desafios. Considerar $n=20$ professores.

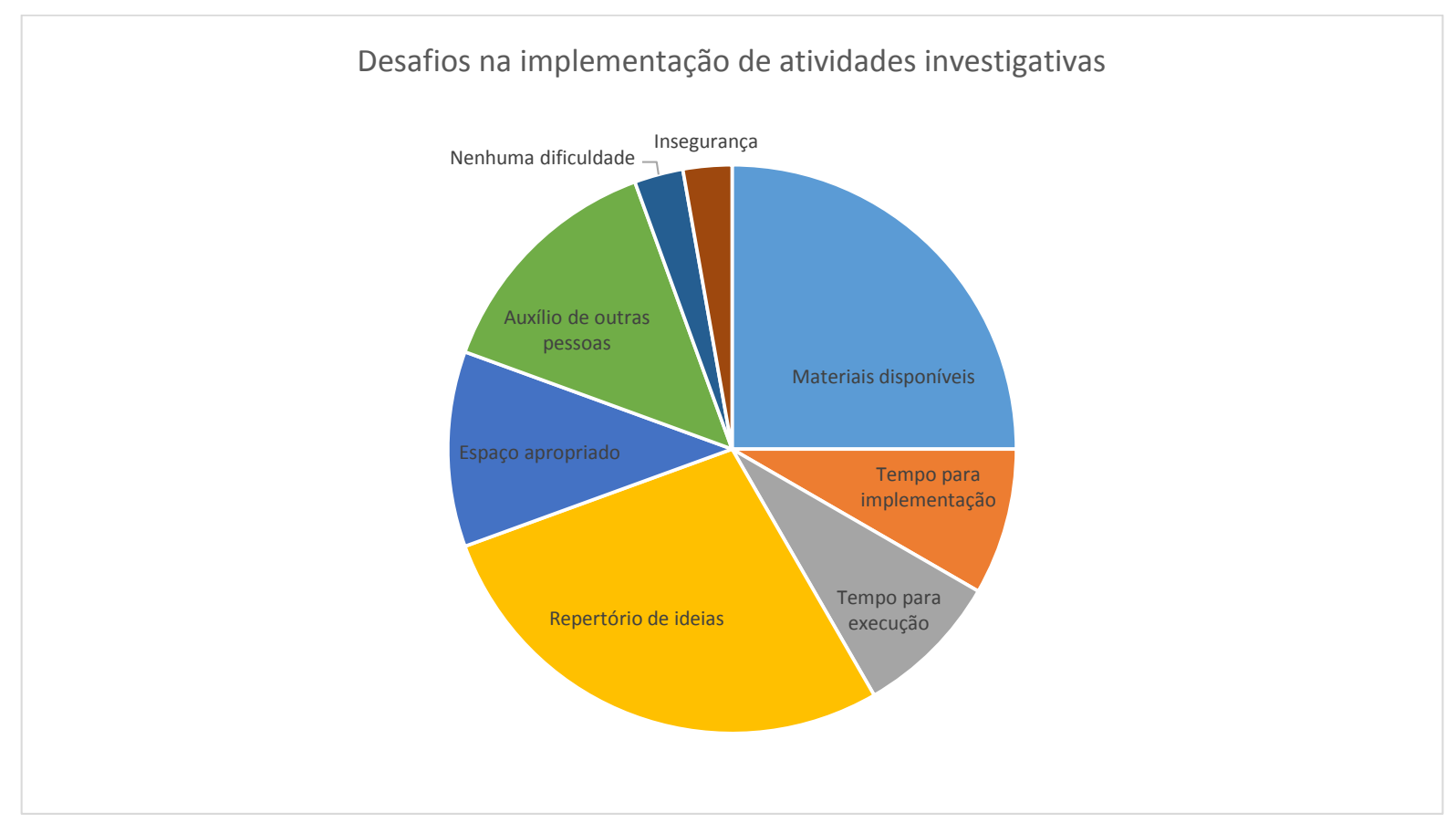

Fonte: dados da pesquisa.

Grande parte dos professores considera que há poucos materiais disponíveis ou de fácil acesso (9 de $n=20$ ). Ramos e Rosa (2008) apresentam o relato de professores com dificuldades similares, onde há poucos materiais disponíveis e falta incentivo para que eles sejam utilizados. Com escassez de material, tais professores teriam de planejar e produzir os seus próprios materiais. Outro fator que também foi pontuado é o tempo para implementação e execução das Als (3 de $\mathrm{n}=20$ ). É possível que tais professores tenham dificuldades em elaborar sequências didáticas que envolvam investigação em sala de aula e, por isso, podem acabar dependendo de um repertório 
de ideias. No entanto, os professores apresentam esse fator como um desafio, sendo o repertório de ideias escasso (10 de $n=20$ ). Posteriormente serão apresentados dados que podem dar mais força para essa inferência.

Os professores consideram a importância de um espaço apropriado para executar essas atividades (4 de $n=20$ ), como um laboratório de Ciências ou uma sala especial. Além disso, o auxílio de outras pessoas ( 5 de $n=20$ ) para ajuda-los, como estagiários ou professores auxiliares, foi outro fator apontado. Por fim, há também aqueles que apontaram nenhuma dificuldade ao implementar as Als (1 de $n=20$ ). Houve ainda uma professora que mencionou o fato de sua insegurança na implementação (1 de $n=20$ ), podendo ser falta de conhecimento conceitual ou de conhecimento sobre a modalidade didática em questão (ensino de Ciências por investigação). Abd-El-Khalick et al. (2004) afirmam em sua pesquisa que os professores dos primeiros anos de escolarização podem apresentar insegurança ao desenvolver os conteúdos de Ciências com os alunos, enquanto aqueles que lecionam nos anos finais, por serem professores especialistas, apresentam mais segurança.

Conforme anteriormente mencionado, dentro desse grupo de participantes foi constatado que 35\% (7 de $n=20$ ) dos sujeitos desta pesquisa não aplicaram atividades investigativas nenhuma vez no ano passado (Figura 1). Neste momento, serão apresentados e discutidos os principais motivos e as dificuldades apresentadas pelos professores que não aplicaram atividades investigativas no ano anterior. Todavia, a possibilidade dos professores participantes desta pesquisa não conhecerem o que são atividades investigativas deve ser levada em consideração ao analisar-se esses dados das concepções prévias.

É importante lembrar que os dados apresentados a seguir têm $n=7$, pois neste momento será considerado apenas as respostas de professores que não aplicaram Al. Com a análise de conteúdo das respostas, foi evidenciada a falta de espaço apropriado para realizar Als como um dos principais fatores que impedem a implementação (4 de $n=7)$. Comparando-se os dois gráficos, nota-se um $\mathrm{n}$ igual para este desafio, o que revela que todos aqueles que a apontaram estão entre os que dizem não ter colocado atividades investigativas em prática no ano anterior. Contudo, não sabemos se tais professores não as implementaram alguma vez, pois foi perguntado somente sobre a frequência de aplicação do ano anterior para se ter uma ideia de sua prática atual. 
A falta de materiais disponíveis, a falta de tempo para planejamento e o repertório escasso de ideias seguem como as dificuldades mais citadas ( 3 de $n=7$ ). Dentre essas, o tempo para planejamento de atividades investigativas foi uma dificuldade apontada pelos professores que não aplicaram Als no ano anterior. Uma possível conexão com esses resultados seria o tempo escasso para planejar tais atividades. Os professores podem ter grandes jornadas de aulas com poucas horas disponibilizadas para o planejamento e elaboração de atividades e isso pode limitá-los aos materiais que já foram produzidos e/ou divulgados. Quando esses recursos não estão disponíveis, facilitando o acesso do professor, essa proposta inovadora de atividades acaba ficando sem uso. No entanto, essa dificuldade pode ser subjetiva, pois os docentes podem estar falando tanto de materiais para desenvolver as atividades (como papeis, terra, argila, sementes, entre outros) ou de material de orientação (como livros de formação ou material de orientação).

Campos et al. (2012) e Rosa, Perez e Drum (2007) apontam, em suas pesquisas, professores que apresentaram dificuldades em encontrar material de apoio para o ensino de Ciências, principalmente os conteúdos relacionados com os conhecimentos da Física. Além da falta de materiais disponíveis, Abd-el-khalick et al. (2004) atentam para a qualidade daqueles materiais disponíveis em diversas fontes, como os livros didáticos. Os autores afirmam que a qualidade do material é um fator importante que precisa ser considerado. Por exemplo, eles alertam sobre atividades que valorizam a ação manipulativa a despeito da ação intelectual, ou seja, atividades nas quais os alunos apenas seguem protocolos ou manipulam objetos sem refletirem sobre aquilo que fizeram. Em Meireles et al. (2014) é relatado o um caso de uma professora que utiliza o livro didático nas Als para investigação.

Outros professores ( 2 de $n=7$ ) consideram a falta de auxílio de outras pessoas, como estagiários ou auxiliares de classe, e o tempo para a execução das atividades como desafios na implementação de atividades investigativas. Por fim, uma docente afirma que não implementou atividades investigativas no ano anterior porque não era a professora titular da turma, estava atuando como contratada.

\subsection{Concepções após a intervenção pedagógica}

Para a construção deste tópico, foram utilizadas as transcrições das videogravações do segundo encontro da oficina de formação e tais dados foram cruzados com outras informações respondidas 
no formulário de concepções prévias. Esperavam-se dados adicionais sobre o quanto o curso foi promovendo o desenvolvimento das concepções dos cursistas e sobre as possibilidades e os desafios que aqueles professores enfrentavam na prática. Com isso, obteve-se o seguinte quadro de dificuldades e possibilidades (Tabela 1):

Tabela 1. Análise de dados apresentados pelos professores no primeiro encontro. Considerar $\mathrm{N}=09$ professores presentes no segundo dia de formação.

\begin{tabular}{|c|}
\hline DIFICULDADES \\
\hline Aproveitar o erro nas atividades investigativas. \\
\hline Administrar a euforia das crianças durante a atividade. \\
\hline Adaptação à rotina. \\
\hline $\begin{array}{c}\text { Vislumbrar a possibilidade de trabalhar a Língua Portuguesa e a Matemática junto ao } \\
\text { ensino de Ciências. }\end{array}$ \\
PossıBILIDADES \\
\hline Possibilitar a atuação mais autônoma do aluno no processo de aprendizagem. \\
\hline Dar autonomia discente para a criação de novas pergunta e da metodologia da \\
pesquisa. \\
Atrelar ensino de Ciências ao ensino de outras disciplinas.
\end{tabular}

Fonte: dados da pesquisa.

A professora 15 não realizou nenhuma atividade investigativa no ano anterior. No entanto, ela relata que realizou atividades similares antes com o tema germinação e crescimento de sementes, mas ela não a considerou como uma atividade investigativa. A professora apresentou, no formulário de concepções prévias, diversos desafios que a impossibilitaram de implementar atividades investigativas no ano anterior, como a falta de materiais disponíveis, falta de auxilio de outras pessoas, repertório de ideias escasso, falta de tempo para planejamento da atividade investigativa e falta de tempo para execução da atividade investigativa.

Quanto ao tempo para execução, em Abd-El-Khalick et al. (2004) é encontrado o relato de professores Taiwanês que sofrem pressões que dificultam a implementação das atividades investigativas. Eles afirmam que os professores de Ciências acreditam que sua função é cumprir todo o conteúdo que está no livro didático para que os alunos possam obter bons resultados em testes futuros. Então, tais docentes argumentam que o tempo para a implementação de atividades investigativas é inviável, em vista das outras modalidades didáticas. Em Malheiro e 
Fernandes (2015) também são encontrados professores colocando o tempo e a pressão diária com o cronograma e currículo escolar como uma dificuldade.

Contudo, a professora consegue aplicar uma atividade experimental investigativa a seus alunos após o primeiro dia de formação. Ela afirma: "então, eu fiz com os alunos do quinto ano, a gente fez a atividade da mosca-das-frutas, e... Só que não deu certo". A professora realizou uma Al que necessitava de pouco recurso e espaço físico e, em sua fala, demonstra dificuldade em lidar com os "erros". Ela poderia ter aproveitado a situação para iniciar uma nova discussão ou uma nova investigação em cima dos resultados obtidos, no entanto, ela começa a refletir sobre essa possibilidade após a discussão no curso de formação. Aparentemente, a professora esperava um resultado e obteve outro e classificou isso como um erro em sua atividade.

Posteriormente, a professora formadora alerta para um outro olhar sobre o erro em Als, já que afirma: "bom, depois a gente vai falar sobre essa questão de quando dá errado". A professora 15 reflete sobre a questão e afirma: “a gente aprende com o erro também, né?". Neste momento, a professora demonstra compreender que o fato de o experimento realizado não ter atendido às suas expectativas não o torna errado, na verdade, o desafio apontado surge como uma possibilidade.

Quando os experimentos não demonstram resultados conforme as expectativas, ocorre uma oportunidade para que o professor trabalhe com novas hipóteses, onde os alunos podem partir para novas investigações, pesquisando o motivo de não terem chegado ao resultado esperado. Segundo Borges (2002), quando as causas dos "erros" não são investigadas em tais atividades, o professor perde uma potencial e valiosa situação de aprendizagem. Além disso, o autor afirma que muitas vezes tal perca pode ser por falta de tempo.

Ao realizar uma atividade investigativa em uma área verde, dentro da escola, a P19 se sentiu desconfortável com a reação das crianças. Os alunos deveriam coletar folhas de variadas plantas para posterior análise em uma atividade investigativa de classificação. A professora relata: "então, assim, foi legal, mas acho que eles deviam fazer mais vezes para acalmar um pouco, para que isso não seja esse 'BUUMM'! Essa novidade". No formulário de concepções prévias, a professora relatou que em sua escola não há espaço específico para realizar as experiências de Ciências, contudo, conseguiu aplicar uma Al dentro do próprio espaço escolar. 
Ela pensou que a euforia dos alunos atrapalhou, todavia, os alunos desenvolveram o que era proposto. Naturalmente, a professora ficou preocupada com a segurança das crianças, que se espalharam pela escola para realizar a atividade. Uma alternativa a ser testada para superar este desafio seria planejar a atividade restringindo o espaço de estudo dos alunos. Apesar de não ser possível em todos os casos, a ajuda de um estagiário ou uma segunda pessoa também poderia auxiliar caso o objetivo seja investigar um espaço mais amplo. No entanto, nem sempre tais professores contam com esse auxilio. Nesses casos, é necessário o estabelecimento de "contratos didáticos" ou de regras bem estabelecidas, postas de maneira firme e clara aos alunos, a fim de se evitarem situações eufóricas que atrapalhem o andamento da atividade.

A afirmação de $\mathrm{P} 1$, de que uma rotina sobrecarregada de atividade é um dos principais desafios enfrentados por ela em sua prática foi consenso entre os professores. Ela e as outras professoras afirmam:

P1: Foi a rotina mesmo.

P7: Porque é fechamento do bimestre, né?

P1: Principalmente é isso, de ter feriado, então assim, mas por conta mesmo da rotina, dessa rotina, feriado e aí época de sondagem.

P19: Então, o que eu fiquei um pouco assim é essa questão do tempo, é uma questão que pega muito. Por que assim, todo mundo cobra muito na escola Matemática e Língua Portuguesa, então é isso que você tem que girar. E Ciências, por mais que você trabalhe Matemática e trabalhe produção de texto, acaba ficando com um horário mais restrito.

De fato, todas essas questões são autênticas e já foram discutidas anteriormente. Os professores dos Anos Iniciais podem ter grandes demandas e esse fator unido a duplas jornadas de trabalhos, acúmulos de cargos e poucas horas para planejamento pode ser um desafio. No entanto, uma possível alternativa para abrandar tais desafios seria o bom planejamento. Esse momento não necessariamente tem de ser demorado, no entanto, deve ser bem elaborado. Nem todas as atividades investigativas precisam ser implementadas em sequencias didáticas longas, já que há aquelas curtas, que podem ser implementadas em alguns minutos e também aquelas que duram duas aulas ou mais. Quando a atividade é pensada no momento do planejamento anual ou bimestral é possível amenizar o choque com a rotina, pois há bimestres ou trimestres mais comprometidos ou cheios de eventos que outros. 
No relato das professoras explicitado anteriormente, a P19 apresenta a questão da super cobrança das disciplinas de Português e Matemática. Há, de fato, uma supervalorização do ensino da língua materna e da Matemática nos Anos Iniciais de escolarização (RAMOS; ROSA, 2008, ROSA; PEREZ; DRUM, 2007). Os professores podem até criar uma hierarquia entre tais disciplinas, sendo Ciências considerada uma matéria decorativa e menos importante frente às outras (RAMOS; ROSA, 2008). Muitas vezes, os professores utilizam $2 / 3$ do bimestre para trabalhar Português e Matemática e apenas $1 / 3$ para trabalhar Ciências e as demais disciplinas, como revela o relato alçado na pesquisa de Rosa, Perez e Drum (2007).

Contudo, há relatos na presente pesquisa e na literatura que mostram que é possível trabalhar a produção de texto, conhecimento matemático, Artes e outras disciplinas atreladas ao ensino de Ciências por meio das atividades investigativas (NUNES; JULIO, 2013; OLIVEIRA, 2009; OLIVEIRA; CARVALHO, 2005; SOUZA, 2010). A professora 19 confirmou isso e, quando cita uma atividade investigativa que implementou, afirma: "aliás, eles desenharam, os relatórios que eles fizeram eu posso até tentar trazer na próxima aula". Esse relato apresenta um bom caminho de iniciar-se uma ação interdisciplinar em uma atividade investigativa, pois revela que é possível desenvolver habilidades de outras disciplinas atreladas ao ensino de Ciências por investigação

Outro exemplo de possibilidade é evidenciado pela P7, que relata, no segundo dia da oficina, que ficou muito satisfeita com os resultados obtidos em sua turma. Trata-se de uma turma de terceiro ano dos Anos Iniciais, entretanto, os alunos apresentavam dificuldades similares às de alunos de segundo ano. A professora aplicou uma atividade na qual os alunos deveriam investigar fenômenos ligados às cores secundárias, e a P7 ficou muito feliz ao ver o bom desempenho dos alunos e ao se deparar com a autonomia que ela tinha dado a eles. Ela afirma: "e eu vi que eles ficavam tão independentes, eles se soltaram e eles arrasaram. Foi muito legal e eles fizeram o registro e tudo". Sasseron (2015) afirma que investigar um problema possibilita ao estudante desenvolver e praticar sua liberdade e autonomia intelectual.

Durante a atividade anteriormente citada, um aluno decidiu misturar as cores e criar novas perguntas de investigação, como por exemplo: "qual ação eles deveriam tomar para que as cores ficassem mais claras ou mais escuras?" Isso é um exemplo de situação que demonstra que os alunos podem propor novos problemas e a metodologia da atividade investigativa. Isso é a 
consequencia da autonomia concedida pela professora. Nesta atividade descrita, o problema inicial de investigação proposto pela professora era: "quais cores a gente precisaria para formar as cores secundárias" (P7). Deste modo, a ação dos alunos se aproxima daquela atividade desenvolvida pelos pesquisadores, onde podem surgir diversas investigações oriundas de uma pesquisa inicial.

Trivelato e Tonidandel (2015) afirmam que as atividades investigativas não pretendem apenas a construção de conteúdos conceituais, ou seja, a aprendizagem de conceitos. Uma característica dessas atividades é a preocupação com a inclusão do aluno na cultura científica, com atividades que visam a desenvolver habilidades próximas do "fazer científico". Ou seja, realizar observações, propor hipóteses, manusear materiais, manipular dados, realizar experimentos, fazer pesquisas bibliográficas, propor conclusões ou considerações, entre outros. Além disso, os alunos são motivados também a refletir, discutir, registrar, relatar e criar novas perguntas a partir daquilo que foi investigado. O que se aproxima muito da atividade do cientista. Nesse mesmo contexto da atividade da P7 - das cores secundárias - a professora dá um exemplo da empolgação dos alunos quando estão envolvidos nesse tipo de trabalho. Ela diz:

[...] tanto é que na aula de informática, foi bem engraçado, que tem uns joguinhos lá deles, e eu cheguei na sala e estava tudo diferente, e aí eu perguntei para o professor de informática e aí ele falou: "olha, eles vieram para sala pedindo para pesquisar informações sobre as cores". Então assim, foi deles, foi espontâneo deles, por que eu não pedi a pesquisa das cores.

Os alunos ficaram tão motivados com a atividade que continuaram a investigação em outros momentos. Na aula de informática, eles poderiam jogar o game educativo proposto pelo professor da disciplina, no entanto, de forma autônoma e sem a solicitação da professora, começam a pesquisar na internet informações complementares sobre o fenômeno que eles estudaram na sala de aula. Na literatura, são encontrados trabalhos que relatam o potencial motivador das Als. Um exemplo pode ser encontrado na pesquisa de Soares et al. (2013), na qual eles perceberam o papel fundamental das atividades investigativas experimentais na motivação discente.

Em Malheiro e Fernandes (2015), são encontrados professores apresentando a possibilidade anteriormente discutida, pois eles reconhecem que o caráter prático das atividades investigativas e até o fato de os alunos serem divididos em grupos os motivam para as aulas de Ciências, nas 
quais eles podem realizar novas relações e descobertas. No entanto, há quem defenda que não é em todos os momentos que as atividades práticas terão esse caráter motivador (HODSON, 1994). Segundo Hodson (1994), atividades nas quais os alunos apenas seguem procedimentos e protocolos pré-determinados, no estilo "receita de bolo", tendem a ser menos motivadoras aos estudantes. Em tais atividades, segundo Hofstein e Lunetta (2004), os alunos seguem essa lista de protocolos ritualisticamente e não se envolvem em pensar sobre os efeitos de sua investigação e as consequências das ações que fizeram.

A professora 7 aplicou uma atividade investigativa na qual os alunos deveriam acompanhar o desenvolvimento da Mosca-das-frutas (Drosophila melanogaster). Nessa atividade, seus alunos demostraram muita autonomia, propondo o percurso metodológico da investigação. A professora ficou surpresa com a profundidade das observações realizadas por eles. De acordo com ela: "eles falavam o tamanho que tinha o bichinho, que ele era tonto, só que era rápido. E eles perceberam que quando o bichinho estava voando na subida inclinada, o inseto não conseguia levantar voo". Os alunos investigaram e relataram com detalhes o vôo, agilidade e outras características relevantes do comportamento deste inseto.

A professora 7 também aliou a atividade investigativa com a produção textual e isso estimulou a participação dos alunos. Carvalho (2013) afirma que é possível compreender o entusiasmo dos alunos em atividades em grupo à luz das ideias de desenvolvimento proximal de Vigotsky. Segundo a autora, nessas atividades os alunos estão dentro da mesma zona de desenvolvimento real, sendo assim, conseguem explicar e compreender fenômenos de maneira mais fácil e, nesta interação, podem desenvolver em grupo suas habilidades. A P7 afirma:

[...] nossa, deu até briga para escrever. Quem ia escrever? Tanto é que tem várias letras, por que eles decidiram em grupo que eles iam escrever um pouquinho cada um, então eles iam vendo o que acontecia, e aí um escrevia e depois passava ao outro, e eles se ajudavam, foi tão legal.

A professora 19 também conseguiu aliar o ensino de Ciências com a produção textual na atividade em que os alunos deveriam coletar e classificar folhas de distintas plantas. A professora afirma: "eles desenharam e os relatórios que eles fizeram eu posso até tentar trazer na próxima aula. Elaboraram uma lista das diferenças. Depois, eles fizeram um quadro e de sessenta, eles escolheram nove para desenhar". Viecheneski, Lorenzetti e Carletto (2012) afirmam que quando o 
ensino de Ciências é articulado com produção textual, contribui com a contextualização e a significação das atividades de leitura e escrita. O desenho foi aproveitado como uma alternativa diferenciada de registro.

Gouw, Franzolin e Fejes (2013) também relatam uma experiência similar, na qual os alunos que estavam iniciando o Ensino Fundamental trabalhavam as atividades investigativas e realizavam desenhos para uma posterior comparação e discussão. Campos et al. (2012) afirmam que é importante ensinar Ciências pelo fato de essa ser uma disciplina integradora. Além disso, os autores citam que a literatura recomenda o ensino de Ciências para superar a fragmentação e isolamento das disciplinas.

\section{CONSIDERAÇÕES FINAIS}

A presente pesquisa reforça uma possibilidade já evidenciada pela literatura de referência: a possibilidade de implementação de atividades investigativas no ensino de Ciências a alunos dos Anos Iniciais. Os professores podem enfrentar algumas dificuldades na implementação, conforme foi evidenciado anteriormente, no entanto, foram encontrados professores implementando atividades investigativas. Com isso, alguns futuros trabalhos podem se aprofundar neste fenômeno de implementação, a fim de investigar se há, em diferentes contextos, outros desafios e possibilidades não evidenciados aqui.

As possibilidades trazidas à tona no presente trabalho contribuem como solução para diversos problemas do ensino apontados pela literatura, como, por exemplo, a fragmentação do ensino. Assim, foi demonstrado que as atividades investigativas podem ser integradoras e,em uma atividade investigativa, podem possibilitar o desenvolvimento de habilidades de Ciências, Português e Artes. Em tais atividades, o professor pode desenvolver a autonomia discente, possibilitando ao aluno desenvolver novas perguntas de investigação e sua metodologia. Há relatos, na presente pesquisa, que demonstram que tais atividades podem ser mais motivadoras aos estudantes.

Referente aos desafios apresentados na implementação, os professores demonstraram consciência da importância das atividades investigativas, no entanto, consideram que há pouco material de apoio disponível para se trabalhar tais atividades. No entanto, não foi possivel 
evidenciar aqui se os docentes estavam falando de materiais para realizar as atividades ou material de apoio que os fundamentem para a implementação.

Outro desafio expresso foi a falta de estrutura física nas escolas para se realizar as investigações, já que os professores consideraram importante um espaço apropriado para a realização de tais atividades. Há atividades investigativas nas quais os docentes necessitam de um laboratório com vidrarias adequadas. Entretanto, também há diversas atividades que podem ser realizadas utilizando material acessível ou de baixo custo. Na presente pesquisa, foram apresentados professores que apontavam a ausência de estrutura em sua escola, mas que, posteriormente, conseguem pensar em uma atividade com aquilo que a sua escola dispõe. Na literatura, também é possível encontrar alguns exemplos: no relato de Silveira et al. (2014), que utilizou um vídeo para observar aspectos de dois animais ao invés de realizar a observação na natureza, e em Campos et al (2012) que utilizou materiais de fácil acesso para uma experiência a partir de conhecimentos do mundo da física.

Foi evidenciado, na presente pesquisa, que muitos dos desafios apresentados no formulário de concepções prévias foram superados pelos professores e, no segundo encontro do curso de formação, eles trouxeram relatos de diversas possibilidades e adaptações que conseguiram realizar. Professores que antes questionavam a ausência de espaço apropriado ou material disponível conseguiram implementar atividades investigativas utilizando recursos alternativos e evidenciaram diversas possibilidades na implementação.

Em vista dos resultados apresentados na presente pesquisa, é importante reforçar a necessidade da multiplicação de pesquisas empíricas que analisem fenômenos relacionados às atividades investigativas. Tais pesquisas embasariam futuros trabalhos e documentos oficiais que regem a educação, reforçando a literatura de referência. Além disso, a discussão dos desafios com a valorização das possibilidades contribuiria com o trabalho de professores que decidam implementar as atividades investigativas em sua prática. Essas investigações trariam contribuições também para o aperfeiçoamento do método de ensino de Ciências por investigação. Por fim, outro campo aberto para pesquisas seria a realização de estudos de casos ou pesquisas-ações, investigando cada possibilidade e desafio individualmente, tentando encontrar evidências em um campo mais específico. 


\section{AGRADECIMENTOS}

Os autores deste trabalho agradecem à Pró-Reitoria de Extensão da Universidade Federal do $A B C$ e à CAPES (Coordenação de Aperfeiçoamento de Pessoal de Nível Superior) pelo apoio, fomento e financiamento às atividades de ensino, pesquisa e extensão nas quais os autores desta pesquisa estão envolvidos.

\section{REFERÊNCIAS}

ABD-EL-KHALICK, F.; BOUJAOUDE, S.; DUSCHL, R.; LEDERMAN, N.G.; MAMLOK-NAAMAN, R.; HOFSTEIN, A.; NIAZ, M.; TREAGUST, D.; TUAN, H.L. Inquiry in Science Education: International Perspectives, Science Education, v. 88, 2004.

BARDIN, L. Análise de conteúdo. Lisboa: Edições 70, 2011.

BORGES, A.T. Novos Rumos para o Laboratório Escolar de Ciências. Caderno Brasileiro de Ensino de Física, Santa Catarina, v. 19, n.3. p.291-313, dez. 2002.

BYBEE, R. W. Teaching science as inquiry. In: MINSTRELL, J.; VAN ZEE, E. Inquiring into inquiry learning and teaching in science. Washington: American Association for the Advancement of Science, 2000. p. 21-46.

CAMPOS, B.S; FERNANDES, S.A.; RAGNI, A.C.P.B; SOUZA, N.F. Física para crianças: abordando conceitos físicos a partir de situações-problema. Rev. Bras. Ensino Fís. São Paulo, v.34 n.1, P. 1402/1-140/15, 2012.

CAPECCHI, M.C.V.M. Problematização no ensino de Ciências. In: CARVALHO, A.M.P. (org.). Ensino de Ciências por investigação: condições para implementação em sala de aula. São Paulo: Cengage Learning, 2013. Cap.1, p.1-20.

CARVALHO A.M.P. O ensino de Ciências e a proposição de sequências de ensino investigativas. In: CARVALHO, A.M.P. (Org.) Ensino de Ciências por investigação - Condições para implementação em sala de aula. São Paulo: Cengage Learning, 2013.

A. M. P.; GIL-PEREZ, D.; Formação de Professores de Ciências: tendências e inovações. São Paulo: Cortez Editora, 1993.

A.F.; LABURÚ, C.E. Atividades investigativas no ensino de Ciências: Aspectos históricos e diferentes abordagens. Revista Ensaio, Belo Horizonte, v.13, n.3, p.67-80, 2011.

A.M.P. (Org.) Ensino de Ciências por investigação - condições para implementação em sala de aula. São Paulo: Cengage Learning, 2013.

A.M.P. Ciências no Ensino Fundamental. Caderno de Pesquisa, Maranhão, n.110, p.153-168, jul. 1997.

A.M.P. O ensino de Ciências e a proposição de sequências de ensino investigativas. In: (org.). Ensino de Ciências por investigação: condições para implementação em sala de aula. São Paulo: Cengage Learning, 2013. Cap.1, p.1-20.

COLOMBO JUNIOR, P.D. et al., Ensino de Física nos Anos Iniciais: Análise da argumentação na resolução de uma "atividade de conhecimento Físico". Investigações em Ensino de Ciências, Rio Grande do Sul, v.17(2), p. 489-507, 2012.

GIL-PEREZ, D. Contnibución de la História y de la Filosofta de las ciencias al desarrolo de un modelo de enseñanza/aprendizaje como investigación. Enseñanzade las Ciencias, 11(2), 197-212. 1993. 
GODOY, A. V.; SEGRRA, C. I.; MAURO, M. F. Una experiencia de formación docente en el área de Ciencias Naturales basada en la indagación escolar. Revista Eureka Sobre Enseñanza y Divulgación de Las Ciencias, Cádiz, v. 11, n. 3, p.381-397, 2014.

GOUW, A.M.S.; FRANZOLIN, F.; FEJES, M.E. Desafios enfrentados por professores na implementação de atividades investigativas nas aulas de Ciências. Ciência \& Educação, Bauru, v. 19, n. 2, p. 439-454, 2013.

HODSON, D. Hacia un enfoque más crítico del trabajo de laboratorio. Ensenãnza de las Ciências, v.12, n.3, 1994.

HOFSTEIN, A.; LUNETTA, V.N. The laboratory in science education: foundations for the twenty-first century. Science Education. v. 88, n.1, 2004.

KRASILCHIK, M; MARANDINO, M. Ensino de Ciências e cidadania. 2 ed. São Paulo, Moderna, 2007. 87p.

LAMONATO, M.; PASSO, C.L.B. "Siga os exemplos" dos alunos: aprendizagens em aulas exploratório-investigativas no 4ㅇa ano do ensino fundamental. Revista Eletrônica de Educação, São Carlos, v. 6, n. 1, maio 2012.

LUDKE, M. \& ANDRÉ, M.E.D.A. Pesquisa em educação: abordagens qualitativas. São Paulo, Editora Pedagógica e Universitária, 1986.

MALHEIRO, J.M.S. FERNANDES, P. O recurso ao trabalho experimental e investigativo: percepções de professores de Ciências. Investigações em Ensino de Ciências, V.20, n.1, 2015.

MARSHALL. C; ROSSMAN, G; B; Designing Qualitative Researrch. Thousand Oaks: Sage Publications, 2006.

MATOS, M.G.M.; VALADARES, J. O efeito da actividade experimental na aprendizagem da Ciência pelas crianças do primeiro ciclo do ensino básico. Investigações em ensino de Ciências, v.6, n. 2: pp. 227-239, 2001.

MEIRELES, S. M.; Camargos, T. C. C. ; BOSCO, C. S. ; SOUTO, K. C. N. . O bicho-pau na sala de aula: construindo uma proposta investigativa com crianças de seis anos. Revista de Ensino de Biologia da Associação Brasileira de Ensino de Biologia (SBEnBio), v. 7, p. 6735-6745, 2014.

MINSTRELL, J. and van ZEE, E.H. Inquiring into Inquiry Learning and Teaching in Science. Washington, DC: American Association for the Advancement of Science, 2000.

MORTIMER, E.F. Linguagem e Formação de Conceitos no ensino de Ciências. Belo Horizonte: Ed. UFMG, 2000.

NATIONAL RESEARCH COUNCIL. National science education standards. Washington, DC: National Academy, 1996. Disponível em: (www.nap.edu/openbook.php?record_id=4962\&page=23). Acesso em: 2 fev. 2015.

NUNES, M.B.T.; JULIO, J.M. A produção escrita como estruturadora em aulas investigativas de ciências no 5o ano do ensino fundamental. In: Atas do IX Encontro Nacional de Pesquisa em Educação em Ciências, 9, 2013, São Paulo. Anais do IX ENPEC. Águas de Lindóia, SP, 2013.

OLIVEIRA, C.M.A.; CARVALHO, A.M.P. Escrevendo em aulas de Ciências. Ciência \& Educação, v. 11, n. 3, p. 347-366, 2005.

C.M.A. Do discurso oral ao texto escrito nas aulas de ciências. 2009. 233f. Tese (Doutorado em Educação) - Faculdade de Educação da Universidade de São Paulo, Universidade de São Paulo, 2009.

C.M.A. O que se fala e se escreve nas aulas de Ciências? In: CARVALHO, A.M.P. (org.). Ensino de Ciências por investigação: condições para implementação em sala de aula. São Paulo: Cengage Learning, 2013.

OLIVEIRA, E. et al. Análise de Conteúdo e pesquisa na área da educação. Revista Diálogo Educacional, Curitiba, v. 4, n.9, p.11-27, maio/ago. 2003. 
RAMOS, L.B.C.; ROSA, P.R.S. O ensino de Ciências: fatores intrínsecos e extrínsecos que limitam a realização de atividades experimentais pelo professor nos Anos Iniciais do Ensino Fundamental. Investigações em Ensino de Ciências - v.13(3), pp.299-331, 2008.

ROSA, C.W.; PEREZ, C.A.S.; DRUM, C. Ensino de Física nas séries iniciais: concepções da prática docente. Investigações em Ensino de Ciências, v. 12, n.3, pp. 357-368, 2007.

SASSERON, L.H. Alfabetização Científica, ensino por investigação e argumentação: relações entre Ciências da Natureza e Escola. Revista Ensaio, v.17, n. especial, 2015.

SASSERON, L.H. Interações discursivas e investigação em sala de aula: o papel do professor. In: CARVALHO, A.M.P. (org.). Ensino de Ciências por investigação: condições para implementação em sala de aula. São Paulo: Cengage Learning, 2013.

SOARES, K.C.M.; PAULA, L.M.; PAULA, L.M.; SILVA, R.C.; PEREIRA, G.R. Experimentos de Ciências nos Anos Iniciais do Ensino Fundamental: uma ferramenta para a motivação em sala de aula. In: Atas do IX Encontro Nacional de Pesquisa em Educação em Ciências, 9, 2013, São Paulo. Anais do IX ENPEC. Águas de Lindóia, SP, 2013.

SOUZA, L.S. Compreensão leitora nas aulas de ciências. 2010. 216 f. Tese (Doutorado em Educação) - Faculdade de Educação da Universidade de São Paulo, São Paulo, 2010.

TRIVELATO, S.L.F.; TONIDANDEL, S.M.R. Ensino por investigação: eixos organizadores para sequências de ensino de Biologia. Revista Ensaio, v.17, n. especial, 2015.

VAN ZEE, E.H et al. Learning and Teaching Science as Inquiry: A Case Study of Elementary School Teachers' Investigations of Light. Science Education, v.89, n.6, 2005.

VIECHENESKI, J. P.; LORENZETTI, L.; CARLETTO, M. R. Desafios e práticas para o ensino de Ciências e alfabetização científica nos Anos Iniciais do Ensino Fundamental. Atos de Pesquisa em Educação (FURB), v. 7, p. 853-876, 2012.

WELCH, W., KLOPFER, L., AIKENHEAD, G., e ROBINSON, J. The role of inquiry in science education: Analysis and recommendations. Science Education, 65, 33-50, 1981.

WHEELER, G.F. The Three Faces of Inquiry. In: MINSTRELL, J.; VAN ZEE, E. Inquiring into inquiry learning and teaching in science. Washington: American Association for the Advancement of Science, 2000. p. 14-19.

ZANON, D.A.V.Z; FREITAS, D. A aula de Ciências nas séries iniciais do ensino fundamental: ações que favorecem a sua aprendizagem. Ciências \& Cognição, Rio de Janeiro, v. 10, p.93-103, 2007.

ZOMPERO, A. F.; LABURÚ, C. E. L. As atividades de investigação no Ensino de Ciências na perspectiva da teoria da Aprendizagem Significativa. Revista electrónica de investigación en educación en ciencias, v.5, n. 2, 2010. 


\section{ANEXO}

Anexo I - Perguntas respondidas pelos professores cursistas no formulário de concepções prévias.

1. Para você, o que seria uma atividade investigativa?

2. Marque quantas vezes você realizou atividades investigativas com seus alunos no ano passado

3. Existe algum fator que impediu você de realizar mais atividades investigativas?

4. Cite 3 exemplos de atividades investigativas que você já trabalhou com os estudantes

5. Para que serve uma atividade investigativa e qual a sua importância na formação dos alunos?

6. Caso seja selecionado e a prefeitura de município arque com os custos de transporte e alimentação, você estaria disposto (a) a acompanhar seus alunos durante três visitas, estas a serem realizadas às quartas-feiras, nas dependências da UFXXX, durante o período vespertino (tarde), para desenvolver atividades com a Prof. Coordenadora do Curso e sua Equipe?

7. Se você for professor dos Anos iniciais do Ensino Fundamental, qual período leciona neste nível de Ensino.

8. Caso seja selecionado e a prefeitura de município arque com os custos de transporte e alimentação, você estaria disposto (a) a acompanhar seus alunos durante três visitas, estas a serem realizadas às quartas-feiras, nas dependências da UFXXX, durante o período vespertino (tarde), para desenvolver atividades com a Prof. Coordenadora do Curso e sua Equipe?

9. Que recursos possui na sua escola para realizar experimentos?

10. É possível solicitar facilmente à coordenação ou direção da escola a compra de materiais para a utilização nas aulas?

11. Quais os espaços que sua escola possui para realizar experiências em ciências?

12. Você estaria disposto a colaborar com as pesquisas científicas do nosso grupo, fornecendo acesso aos seus planejamentos, planos de aula, entre outros? 